\title{
Emotional Health in Attention Deficit Hyperactivity Disorder
}

Luis A. Ocaña-Hernandez, Martha A. Delgado-Ochoa*, Carlos Delgado-Hernandez, Giselle AlcalaFernandez, Jose L. Garcia-Elizondo, Penelope Galvan-Heredia and Irene Heredia-Barragan

Department of Pediatric Neurology, Mexican Social Security Institute, Mexico

*Corresponding author: Martha A Delgado Ochoa, Department of Pediatric

Neurology, Mexican Social Security Institute, Mexico.

Received Date: September 11, 2020

Published Date: September 28, 2020

\begin{abstract}
Attention deficit hyperactivity disorder (ADHD) is the most common psychiatric disorder in pediatric age, comorbidities in ADHD are present in two-thirds of patients who attend the mental health service, being emotional disorders one of the most frequent. Comorbidities have implications in the severity, course, response to treatment and prognosis, so we must detect them when diagnosing and treating a patient with ADHD. An observational, descriptive, transversal study was conducted in children with ADHD from April 2012 to October 2013 to determine the frequency of mood and anxiety disorders in clinic 71, of the IMSS in Torreón Coahuila, Mexico, based on DSM IV-TR criteria, Conners Scale and statistical analysis. 115 patients were studied. The frequency of mood disorders found was 77\%. The most prevalent emotional disorder was phobia disorder (48.6\%) followed by major depression (37.4\%) and agoraphobia $26.1 \%$.
\end{abstract}

\section{Introduction}

ADHD is the most diagnosed neurobiological disorder in children, characterized by significant functional deficiencies (immediate and remote) derived from symptoms of inattention, hyperactivity and impulsivity and is the most common psychiatric disorder in pediatric age [1,2]. It constitutes main feature of hyperkinetic syndromes. The patients should be diagnosed only if the symptoms are excessive for the age and the IQ is not affected. The ICD-10 considers onset at 4 years old of age, while the DSM-IV TR considers it at 6 years old of age. The symptoms must appear in two or more environments, preferably it occurs in men, it can be accompanied by alterations in motor skills and language, as well as learning disorders $[3,4]$.

\section{Epidemiology}

Its worldwide prevalence has been estimated between $4-12 \%$ in those under 18 years of age. Between $7.1 \%$ and $12.8 \%$ in the child

population, in Ukraine it had a prevalence of $19.8 \%$, and in Iceland, Australia, Italy, Sweden and Spain the prevalence was between 2.5 and 7.5\%. In Mexico it is estimated that there are around 1,500,000 children with ADHD. It is estimated that for every 100 school-age children, 3 to 5 have ADHD and of 100 patients, 1 to 6 are boys and 1 to 2 are girls; much more frequent in men with differences ranging from 3 to 5 men for a woman [5,6].

Neuroanatomy, neurophysiology and pathophysiology in Attention Deficit Disorder

Dysfunction of the cerebellum-thalamus-prefrontal cortex circuit may intervene in motor control, inhibition and deficits in executive functions in patients with ADHD. Functional studies are related with structural neuroimaging studies in which dysfunction of the fronto-subcortical systems is implicated. The caudate nucleus receives signals from the cerebral cortex and is related with executive functions [3,5]. 


\section{Genetics of ADHD}

ADHD has a strong genetic component, with a heritability approaching $80 \%$ [7]. Its inheritance pattern is not Mendelian but complex, probably contributing more than one gene to a genetic load that provides susceptibilities in interaction with environmental factors. Have been described risk alleles in seven candidate genes with odds ratios that exceed 1.0, that is, they are over-transmitted in ADHD. These include five catecholaminergic genes: dopamine-4 and dopamine-5 receptor (DRD4, DRD5), dopamine transporter (DAT1), dopamine-b-hydroxylase (DBH) and the SNAP-25 gene, and two serotonergic genes: transporter serotonin (5-HTT) and serotonin receptor 1B (HTR1B) [6,8].

\section{Clinical symptoms and diagnosis}

The diagnosis of ADHD is clinical and is based on a personal and family history, also a detailed physical, neurological and mental examination, and on complementary evaluations that support the diagnosis. The diagnostic criteria for ADHD are descriptive and refer to levels of attention, activity, and impulsivity that are inappropriate for the developmental age, and that significantly interfere with school performance, cognitive functioning, social skills or occupational performance, for at least 6 months, in preschool for at least 9 months and that have started at 6 years of age. These criteria has been used for the International classification of Diseases 10th edition (ICD-10) and for the Diagnostic and Statistical Manual of Mental Disorder of American Psiquiatric academy (DSM-IV 1994, DSM-IV-TR 2000). The ICD-10 recognize only hiperquinetic disorder unlike of DSM-IV-TR wich recognize three phenomenological subtypes of ADHD: inattentive, hyperactive-impulsive or combined $[9,10]$ which was the one used in this study due to the date the patient sample was obtained. Currently and since 2013 DSM 5 has been in force, which makes qualitative adjustments to the criteria and changes the age of onset of symptoms to before 12 years of age.

\section{Comprehensive treatment and management}

There are several types of treatments indicated for ADHD in children and adolescents, however the one with the highest levels of efficacy is combined or multimodal treatment, which includes psychological, pharmacological and psychopedagogical intervention. Psychological treatment for ADHD in children and adolescents [3].

Behavior therapy: It is based on a functional analysis of behavior. The factors that are maintaining the inappropriate behavior are identified, the behaviors to be increased, decreased or eliminated are delimited, and they are observed and recorded (baseline). In behavior therapy, the behavior control is external, the behavior is modified depending on the consequences of the behavior $[3,6]$.

Parent training: Behavioral treatment program that aims to provide information about the disorder, teach parents the effective application of the behavior modification techniques mentioned above, increase parental competence, improve the parent-child relationship through better communication and care to the development of the child $[3,8]$.

Cognitive therapy: Training in self-instruction, self-control and problem solving techniques. The objective of these techniques is to teach adolescent and children with ADHD strategies to improve the control of emotions by raising awareness of thought processes, reducing immediate impulsive responses, and applying problemsolving strategies[3,8].

Social skills training: Children and adolescents with ADHD often have family relationship problems, social skill difficulties, and peer relationship problems. Social skills training aims at learning effective behaviors in interpersonal relationships by the child. Social skills sessions are usually done in small groups of similar ages $[2,9]$.

Psychopedagogical treatment for ADHD in children and adolescents

The psychopedagogical intervention aims to improve the academic performance of the child or adolescent (through psychopedagogical re-education) and to carry out those actions aimed at improving their school adaptation (through an intervention program in school and teacher training). Psychopedagogical reeducation is an individualized school reinforcement that takes place after school hours and that aims to intervene on the negative effects of ADHD in relation to their learning and academic competence $[4,9]$.

Pharmacological treatment for ADHD in children and adolescents

a) Central nervous system stimulants:

- Methylphenidate- Potent inhibitor of the presynaptic dopamine transporter. (Ritalin, Tradea, immediate action)

- Methylphenidate (Concerta, Ritalin LA, Tradea LP, extended-release forms)

- $\quad$ Lisdexamfetamine dimesylate. Blocker of the release of dopamine and to a lesser extent of norepinephrine and inhibits its recapture. (Vyvanse)

- Modafinil. Inhibitory activity of dopamine and norepinephrine transporters. (Modiodal, Aditral, Zydilo)

- Bupropion. Noradrenaline and dopamine reuptake inhibitor. (Wellbutrin)

- $\quad$ D, L - amphetamine (Adderall, Benzedrine, Dexedrine) (Not available in Latin America)

- $\quad$ Pemoline (Cylert) [4,11,12] (Not available in Latin America)

b) Non-stimulants of the central nervous system:

- Atomoxetine. Norepinephrine reuptake inhibitor. (Strattera, Masennus, Moxazyd) 
- Imipramine. Tricyclic antidepressant. (Talpramin)

- Venlafaxine. Serotonin and norepinephrine reuptake inhibitor. (Vextor, Mazda).

- Clonidine (Catapresan), guanfacine. Alpha adrenergic agonists.

\section{Attention deficit disorder and hyperactivity and anxiety disorders}

There are many definitions of anxiety, but one that is helpful is, apprehension or excessive fear about real or imagined circumstances. The most important characteristic of anxiety is worry, which is excessive anxiety about situations with uncertain results. Excessive worry is unproductive because it can interfere with the ability to take action to resolve a problem. Symptoms of anxiety can be reflected in thought, behavior, or physical reactions [3]. In preschool and early childhood, children tend to be limited in their ability to anticipate future events, but by mid-childhood and adolescence these reasoning skills are generally developed. There is a tendency for a gradual shift from global, undifferentiated and externalizing fears to more abstract and internal concerns. Up to 8 years of age, children tend to feel anxious about specific, identifiable events, such as animals, the dark, imaginary characters (monsters under their beds), and older children and adults. Young children may fear people that older children find entertaining, such as clowns. After 8 years of age, events that cause anxiety become more abstract and less specific, such as concerns about grades, peer reactions, getting used to a new school, and having friends. Teens can also worry more about sexual, religious, and moral issues. When anxiety becomes excessive then problems with social, personal and academic functioning can arise, resulting in an anxiety disorder. The signs of anxiety disorders are similar in children and adults, although children may have more signs of irritability and inattention $[4,9]$ personal and academic, resulting in an anxiety disorder. The signs of anxiety disorders are similar in children and adults, although children may have more signs of irritability and inattention [4,9]. Personal and academic, resulting in an anxiety disorder. The signs of anxiety disorders are similar in children and adults, although children may have more signs of irritability and inattention $[4,9]$.

\section{Overall objective}

To determine the frequency of mood and anxiety disorders in children with attention deficit and hyperactivity disorder assigned to a highly specialized medical unit no. 71, from the Mexican Institute of Social Security in Torreón Coahuila.

\section{Methodology}

Observational, descriptive, cross-sectional study in children with ADHD, from April 2012 to October 2013. The sample was calculated with the formula of proportions for a finite population with a total of 115 patients, using a convenience sampling. Inclusion criteria: children under 16 years of age, both sexes, ADHD diagnosis. Exclusion criteria, children with degenerative neurological disease, drug use, or epileptic encephalopathies. Data collection based on DSM IV - TR criteria and Conners Scale, the statistical analysis was by descriptive statistics with determination of measures of central tendency, dispersion and frequency measures with the elaboration of graphs and tables to express the results.

\section{Results}

115 patients with ages between 3 and 15 years were studied, the average age was 8.6 years (SD +3 ). The distribution by sex was higher for males by $86 \%$, while for females it was $14 \%$. The frequency found of mood and / or anxiety disorders in the studied group was $77 \%$. The most prevalent emotional disorder was phobia disorder in $48.6 \%$ followed by major depression in $37.4 \%$, the rest of the disorders were distributed as follows, agoraphobia $26.1 \%$, obsessive compulsive disorder in $18.3 \%$, generalized anxiety $15.7 \%$, manic episode in $13.9 \%$, hypomanic episode $9.6 \%$, dysthymic disorder $8.7 \%$, post-traumatic stress disorder $7.8 \%$ bipolar disorder 7\% panic attack 5.2\% (Figure 1 \& 2).

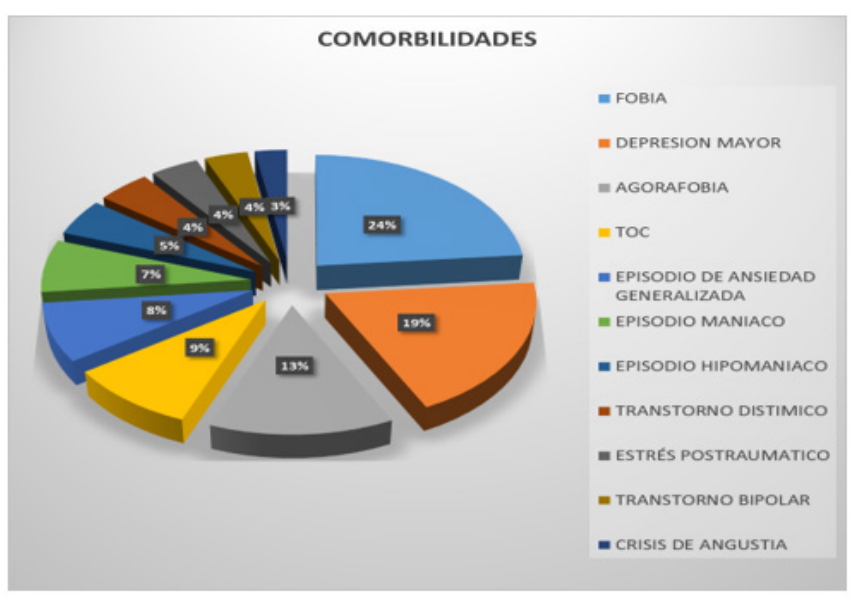

Figure 1: Mood and Anxiety Disorders in Children with ADHD. 


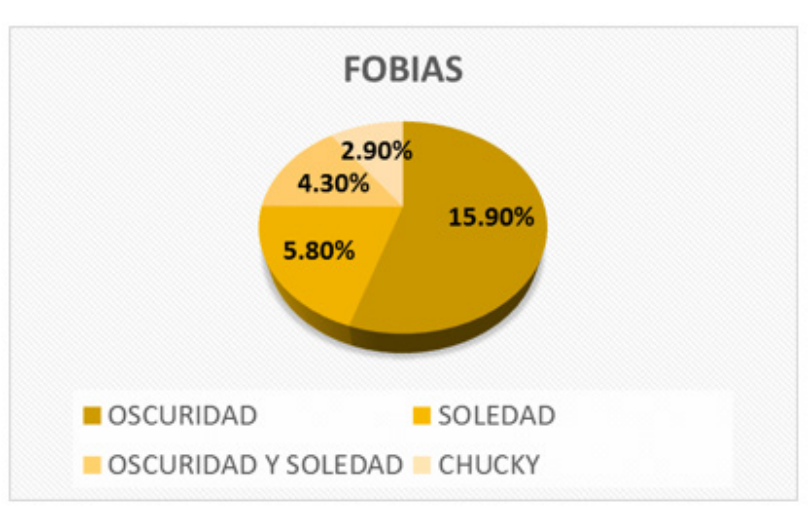

Figure 2: Main Phobias in Children with ADHD.

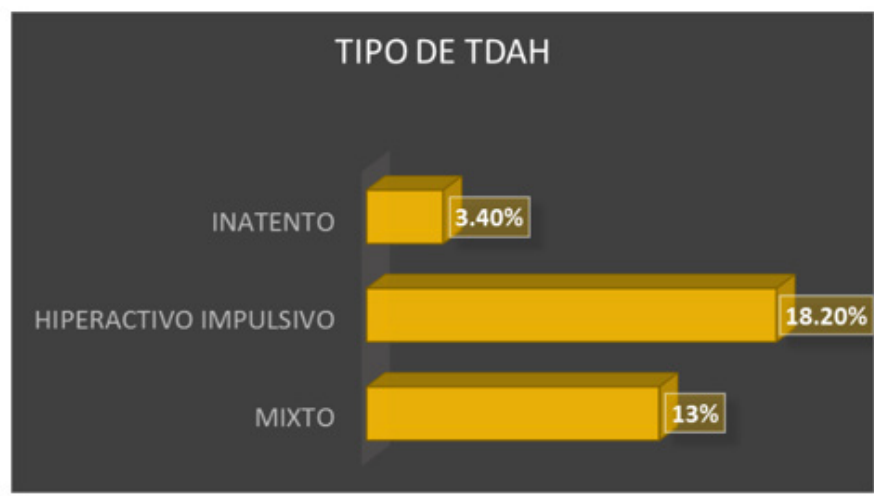

Figure 3: Type of ADHD in Children with ADHD and Depression.

The most frequent type of ADHD in all emotional disorders was the Combined type, followed by the predominantly HyperactiveImpulsive, less frequently the predominantly Inattentive (Figure 3).

\section{Discussion}

As reported by Biederman and Barkley in 2006, the most commonly encountered disorders in ADHD include 50\% oppositional defiant disorder, $30-50 \%$ conduct disorder, $15-20 \%$ mood disorders, and $20-25 \%$ anxiety disorders. In the present study, it was found that $27.8 \%$ of patients have an anxiety disorder, 9.5\% have a mood disorder and $40 \%$ with both and $49.5 \%$ with a mood disorder, which compared to the above give us very high percentages higher $[1,3,13]$. When the differential characteristics between those children with ADHD without anxiety or mood comorbidity are evaluated with those who suffer from it, it is found that the latter have lower self-esteem and worse school and social performance. From what was found in this study, there are patients with a failed year in percentages from $0.8 \%$ to $3.4 \%$ and with school dropouts from $1.7 \%$ to $6 \%$, with the highest percentages in children with phobias and major depression. [9,14].

The importance of mental health in children lies in the fact that at least two-thirds of patients with ADHD who come to receive care have some comorbidity and it has implications in the severity, course, response to treatment and prognosis of the patients, therefore that timely detection is an essential determinant to establish intervention strategies and thus modify the long-term prognosis of the disorder $[15,16]$ in addition to choosing the appropriate treatment according to the predominant symptoms.

\section{Conclusion}

Patients with attention deficit hyperactivity disorder almost always present other accompanying psychopathology, conduct disorders, learning disorders, anxiety and mood disorders, which they suffer at school age, more in males, adequate psychomotor development, from desired pregnancies and without relevant perinatal history in most cases. The anxiety disorders found in this research were mainly phobias in almost half of the studied population followed by major depression, primarily influencing the family environment where both parents work, or have dysfunctional families (violence, economic problems, etc.) where Some of the parents or caregivers also suffer from some untreated psychopathology transmitted to children in addition to the current influence of a chaotic society with excess in stimuli of violent, sexual and consumer content that subjects them to grow up in an unstable environment that demands better daily from them and more performance and fosters competitiveness by creating anxiety, low self-esteem and insecurity from very early stages. The percentages found in this work are much higher compared to other 
bibliographies, perhaps due to the intentional search and the global increase in anxiety and mood disorders in the general population, which is directly reflected in the conditions in children receiving the environment. social and family. Due to what has already been said, it is of the utmost importance to promote adequate mental development for children from the detection of families at risk and the application of specific questionnaires and clinical evaluations for timely diagnoses and to integrate their parents, grandparents and siblings to family and individuals with the support of pediatricians, pediatric neurologists, pedopsychiatrists and psychologists.

\section{Acknowledgement}

None.

\section{Conflict of Interest}

No conflict of interest.

\section{References}

1. Polanczyk G, de Lima MS, Horta BL, Biederman J, Rohde L A (2007) The Worldwide Prevalence of ADHD: A Systematic Review and Metaregression Analysis. Am J Psychiatry 164: 942-948.

2. A Díez Suáreza, A Figueroa Quintanab, C Soutullo (2006) Trastorno por déficit de atención e hiperactividad (TDAH): comorbilidad psiquiátrica y tratamiento Esperón Revista Pediatría de Atención Primaria Vol. VIII.

3. Dra Rosa Elena Ulloa Flores y cols (2010) GUIAS CLÍNICAS, HOSPITAL PSIQUIATRÍCO INFANTIL “DR. JUAN N. NAVARRO” MEXICO DF, PRIMERA EDICIÓN.

4. Egger HL, Kondo D, Angold A (2006) The epidemiology and diagnostic issues in preschool attention-deficit/hyperactivity disorder-A review. Infants and Young Children 19: 109122.

5. Knudsen E (2007) Fundamental Components of Attention. Annu Rev Neurosci 30: 57-78.
6. Crosbie J, Schachar R (2001) Defi cient inhibition as a marker for familial ADHD. Am J Psychiatr 158: 1884-1890.

7. Thapar A, Holmes J, Poulton K, Harrington R (1999) Genetic basis of attention deficit and hyperactivity. Br J Psychiatry 174: 105-111.

8. Chhabildas N, Pennington BF, Willcutt EG (2001) A comparison of the neuropsychological profi les of the DSM-IV subtypes of ADHD. J Abnorm Child Psychol 29: 529-540.

9. Tripp G, Alsop B (2001) Sensitivity to reward delay in children with attention-defi cit/hyperactivity disorder (ADHD). J Child Psychol Psychiatry 42: 691-698.

10. American Psychiatric Association (1994) Diagnostic and Statistical Manual of Mental Disorders, 4th ed. Washington, DC: American Psychiatric Association.

11. Faraone SV, Perlis RH, Doyle AE, Smoller JW, Goralnick JJ, et al. (2005) Molecular genetics of attention-defi cit/hyperactivity disorder. Biol Psychiatry 57: 1313-1323.

12. Faraone SV, Sergeant J, Gillberg C, Biederman J (2003) The worldwide prevalence of ADHD: is it an American condition? World Psychiatry 2: 104-113.

13. Corina B (2004) La depresión con inicio temprano. Salud Publica de México 46: 5.

14. Stefanatos GA, Baron IS (2007) Attention-Defi cit/Hyperactivity Disorder: A Neuropsychological Perspective Towards DSM-V. Neuropsychol Rev 17: 5-38.

15. Kessler RC, Adler L, Barkley R, Biederman J, Conners CK, et al. (2006) The prevalence and correlates of adult ADHD in the United States: Results from the National Comorbidity Survey Replication. Am J Psychiatr 163: 716-723.

16. Schatz DB, Rostain AL (2006) ADHD with comorbid anxiety: A review of the current literature. Journal of Attention Disorders 10(2): 141-149. 